\title{
A CONCEPTUAL FRAMEWORK TO EXPLORE THE ROLES AND CONTRIBUTIONS OF INDUSTRIAL PSYCHOLOGISTS IN SOUTH AFRICA (PART 1)
}

\author{
GRAEME BARNARD \\ LINDA FOURIE \\ lfourie@uj.ac.za \\ Programme in Industrial Psychology \\ Department of Human Resource Management \\ University of Johannesburg
}

\begin{abstract}
This study was aimed at developing a conceptual framework against which the roles and contributions of industrial psychologists in South Africa could be explored. Three widely-used business frameworks - Balanced Score Card, South African Excellence Model and King II Report on Corporate Governance for South Africa - were theoretically integrated to produce a multi-dimensional framework to clarify roles and contributions in a discourse familiar to the business community. The framework was subsequently utilised in a follow-up study involving 23 registered industrial psychologists who were asked to clarify specific roles and contributions within each of the dimensions of the framework.
\end{abstract}

Keywords:

Roles of I/O psychology

A debate regarding the roles and contributions of industrial psychologists, especially in relation to that of the Human Resource Management (HR) practitioner, has been ongoing for some time. Whilst at an academic level, initially at least, a clear distinction was perceived between the two, current realities suggest a large degree of overlap and fusion between them. This apparent overlap and fusion between the roles and contributions of industrial psychologists and HR practitioners have been widely explored and debated among many authors in the field of Industrial Psychology (I/O Psychology) in South Africa over the past number of years, for example Moalusi (2001), Pienaar and Roodt (2001), Schreuder (1999, 2001), Veldsman (2001), Venter and Barkhuizen (2005) and Watkins (2001). Among these authors many reasons for the blurring of the roles and potential contributions have been offered.

The disordered theoretical condition of the academic domain of $I / O$ Psychology in the seventies largely contributed to the confusion and an identity crisis apparently existed among academics and practitioners regarding conflicting psychological theories (Watkins, 2001). The dilemma was further complicated when some universities accepted an academic dispensation where I/O Psychology was taught under the banner of the management sciences and the name and field of study was changed to Personnel Management (and later Human Resource Management or HRM). According to Vermeulen (in Schreuder, 2001) the widely used name Personnel Management for academic industrial psychology courses articulated a strong practical and career-orientated image and the fact that only a few students eventually qualify as industrial psychologists (while a far greater number find themselves in HR positions) further contributed towards the perceived fusion. This created a 'vacuum' in terms of the knowledge base of industrial psychologists that was further eroded by the eventual removal of Consumer Psychology and Ergonomics from the curricula of a number of South African universities, leading to a further limitation of the application potential of the industrial psychologist (Schreuder, 2001). A study by Pienaar and Roodt (2001) confirmed the latter development when participants in their study failed to identify Consumer Psychology and Ergonomics as current or future areas of application for industrial psychologists. In addition to all of the above, the overlap and fusion possibly also developed as a result of the limited and marginal strategic role that industrial psychologists often play in organisational settings, directly or indirectly inhibiting them from making meaningful contributions to the fullest of their potential and ability.

In an attempt to define a clear distinction between I/O Psychology and HR, Schreuder (2001) presented the view that the industrial psychologist's anchor is primarily their theoretical knowledge and research ability in the field of industrial psychology, general psychology, personnel psychology, social psychology, sociology, anthropology and the economic sciences whilst, in contrast, the HR practitioner is chiefly responsible for an organisation's effective utilisation and management of human resources through the implementation of behavioural scientific knowledge. HR practitioners develop and implement systems, practices and policies, in line with the organisation's strategy, to enhance the general effectiveness of their organisations. The knowledge base of HR practitioners, therefore, is industrial psychology, but also the management sciences and labour law (Schreuder, 2001).

The distinction in practice, however, is not all that clear According to Pienaar and Roodt (2001) the practical contributions of industrial psychologists are, amongst others, labour relations, training and development, change management, evaluation or assessment, organisational development, strategic management, career management, selection and placement, psychometric testing, human resources management, counselling and affirmative action. HR practitioners, on the other hand, are mostly involved with labour relations, training and development, strategic management, career management, selection and placement, human resource management, counselling and affirmative action (Gratton, 2000; Ulrich, 1997). The overlap and apparent fusion between the practical roles and contributions of the industrial psychologist and the HR practitioner are clear from the above.

It was against this background of confusion and uncertainty that a further study was undertaken to hopefully add insight and stimulate constructive debate among academic as well as professional communities in the field of I/O Psychology. At this point it was hypothesised that - provided that the roles and contributions of the industrial psychologist could be described in a discourse generally known to the business community - these professionals as well as the users of their services could gain greater clarity regarding the specific and unique roles and contributions of this profession within an organisational 
context. With this objective in mind, the study was designed to develop a conceptual framework against which the roles and contributions of industrial psychologists could be explored, specifically in a 'language' generally familiar to the business community in South Africa at the time.

\section{RESEARCH DESIGN}

In order to overcome the possible limitations of traditional thinking about the roles and contributions of industrial psychologists, now and in the future, the study was designed to approach the question from a different angle. Given the fact that a number of popular business frameworks are widely used in South African to direct and assess organisational activities, it was decided to utilise these frameworks as a background against which the roles and contributions of the industrial psychologists could be clarified in a discourse familiar to the end-user of industrial psychological services. It was argued that if organisations use these existing business frameworks to direct and monitor their business, it would be important to frame the roles and contributions of the industrial psychologist in similar terms.

The attempt to develop a conceptual framework in terms of which the roles and contributions of industrial psychologists could be defined and described resulted from the belief that industrial psychologists could only legitimately claim relevance and importance if it could be demonstrated that they have a valuable role to play and meaningful contributions to make within each of the areas of organisational functioning that are widely perceived to be crucial to organisational success and survival. If the roles and contributions of industrial psychologists could be identified and framed in a discourse familiar to management and business generally, it was assumed that greater role clarity could emerge and greater appreciation could develop among all stakeholders for the value that the profession adds.

Accepting that theory may be developed or understanding may be enhanced through a critical reflection on existing knowledge and further attempts to present reality in a more comprehensive or more accurate manner (Rossouw, 2000; Schwandt, 2001; Van der Merwe, 1996) the study was intended to add value in terms of creating a conceptual framework against which the roles and contributions of the industrial psychologists could be explored. In this context conceptualisation implies both the specifying of dimensions of a concept or notion, and the identification of different indicators thereof (Babbie \& Mouton, 2001). This process is intended to clarify and explain the vague mental images of our concepts and create a generic idea or set of collective characteristics that would define the specific concept or notion (Hair, Babin, Money \& Samuel, 2003; Mouton, 1996; Rossouw, 2000). In this way a common meaning and understanding of a concept (in this instance: the roles and contributions of the industrial psychologist) could hopefully be established.

The social constructionist's view that social roles (by implication, also those of the industrial psychologist) are ultimately socially constructed was fully acknowledged in the design of the study. It was argued that these roles and contributions ultimately have to be defined in a discourse familiar to the organisational context within which industrial psychologists find themselves, in order to be fully acknowledged and understood by all the stakeholders. From this social constructionist's perspective it was further accepted that 'knowing' is active (not passive), that individuals invent concepts, models and schemes to make sense of things, and continue to modify these in light of new experiences (Schwandt, 2001). In this respect culture, language and historical context play an important mediating role in the interpretation and meaning derived from any study of this nature (Willig, 2001). It was therefore acknowledged that the roles and contributions of industrial psychologists defined throughout the different stages of the study would have been mediated historically, culturally and linguistically (Willig, 2001) and that all the assumptions and findings resulting from the study would ultimately be context-bound, having meaning only to those that are part of the specific context.

\section{Research approach}

The stance adopted as a basis for this study aimed to provide scope and freedom to combine aspects from different epistemological views to promote understanding and generate knowledge (Denzin \& Lincoln, 2003, p. 24). At a methodological level this notion may be referred to as a 'mixed method' where multiple strategies (even at a philosophical or pragmatic level) are utilised to generate data and facilitate understanding (Schwandt, 2001). This eclectic approach was chosen in congruence with the view of Patton (2002) who strongly argued that no 'right', best or most useful framework exits and that it would be possible - and even desirable - to present different kinds of evidence or insights generated via multiple methods to address the question of a particular study (p. 135).

A broadly qualitative research approach towards the study was followed. Qualitative research is arguably best suited to research aimed at exploration, elaboration and systemisation of the significance of an identified phenomenon (Banister, Burman, Taylor \& Tindall, 1994; Patton, 2002; Van der Merwe, 1996; Wolcott, 2001). Qualitative methods facilitate the study of issues in depth and detail and are especially useful as a source of grounded theory; theory that emerges from the researcher's inductive and deductive endeavours (Patton, 2002; Van der Merwe, 1996). It was believed that a qualitative approach to the study would allow for insights and understanding to emerge, informing new theory, assumptions or propositions regarding the possible roles and contributions of industrial psychologists. The choice of a qualitative research approach would hopefully allow for data to inform understanding from an interpretative point of view, without prescriptive restrictions in terms of what could or could not be explored. It was further assumed that a qualitative approach focuses on the context and integrity of the data in an interpretative and critical manner (Banister et al., 1994), thereby creating an opportunity for the researcher to be creative and to initiate new ways of finding knowledge (Gergen \& Gergen, 2003; Mauer, 1996; Wolcott, 2001). It was essentially believed that the findings from the study could be useful in developing a conceptual framework against which the roles and contributions of industrial psychologists in the organisation could be 'mirrored', thereby allowing for a creative 'new' look at the roles and contributions that may emerge.

It was necessary to reflect on concerns regarding the reliability, validity and objectivity of the study. Whilst it is widely agreed that concerns of reliability, validity and objectivity are inherent to research of any kind (Mouton, 1996; Patton, 2002; Schwandt, 2001; Willig, 2001) the nature of the qualitative research paradigm implies a reasonable degree of freedom in the interpretation of data and the resultant personal construction of inferred meaning. Researchers working within the qualitative research paradigm acknowledge that there is no certainty in inquiry and accept that perfect degrees of reliability and validity can never be achieved. They, in stead, focus on considerations of trustworthiness or credibility, true value, creativity in the research approach, triangulation and reflection on the research endeavour in its entirety, as well as good practice to overcome these potential problems (Banister et al., 1994; Mauer, 1996; Patton, 2002; Strauss \& Corbin, 1998; Willig, 2001; Wolcott, 2001). A number of strategies were proactively employed to enhance the scientific process involved in this study. As suggested by Patton (2002) data was captured in a way that recorded and preserved the relevant text. Inferences and insights that developed from the literature were substantiated by properly referenced discussions in working documents and emerging themes and insights were captured in user-friendly written format. All these were retained for possible future scrutiny. 
The natural tension between objectivity and subjectivity and the possible influence of a researcher's own interpretation and construction of meaning in the exploratory phases of a qualitative research study was also of particular concern. It this respect it was acknowledged that it is unavoidable that researchers bring to bear a wide range of theoretical, methodological and substantive knowledge (Botha, 1996; Neuendorf, 2002; Willig, 2001) which necessarily influences the findings of any study. Throughout we were aware of these risks as a consequence of our own intense interest in and passion for the subject, and we tried to limit undue subjective influence, especially during the initial analysis and interpretation of the data. To further counterbalance our views discussions with other people (experts as well as lay persons) were undertaken at various stages during the study to test assumptions, exchange ideas about the nature of the problem, and reflect on the emerging findings. These discussions were meant to add meaning and enlightenment to any insights or resultant findings (Snyman, 2000). The final results from the study were submitted for peer review on three occasions.

Despite these efforts, it has to be kept in mind that any theoretical framework developed through a relatively uninhibited analysis and interpretation of data such as was employed in this study would ultimately be subject to different perspectives and interpretation. As a result any analysis and subsequent findings resulting from this study could only reflect a particular way of describing the data and would resultantly be open to reinterpretation of categories, different from the interpretations and labelling arrived at by the researchers (Willig, 2001). This limitation was perceived to be an inherent feature of the specific research approach, and was accepted in light of the fact that the study was an initial exploratory attempt only, aimed primarily at the development of a broad conceptual framework of thinking to aid future research.

\section{Nature of the data}

It was accepted that appropriate data for grounded theory research processes can include texts and documents of varied nature. For this study data consisted of extensive literature on three popular business frameworks. The three business frameworks that were identified to extract theoretical information from on which the development of the intended conceptual framework could be based were the following: Balanced Scorecard (Strategic Management Framework), South African Excellence Model (Continuous Improvement Framework), and King II Report on Corporate Governance for South Africa (Good Corporate Governance Framework). Although it could be argued that not all organisations in South Africa make use of any of these specific business frameworks they are well-known and widelyused. It was further argued that most organisations in South Africa and elsewhere make use of a similar strategic management / continuous improvement / good corporate governance framework to direct and monitor their business, even though it may not be labelled as such. Despite the fact that these informal frameworks may not always be formalised to the extent that the three above-mentioned frameworks are, it was assumed that the underlying premises and themes of each of these frameworks would essentially be similar. The specific three frameworks were thus chosen (1) on account of their popularity and wide-spread use and (2) because it was believed that a workable frame of reference could be derived from these against which the roles and contributions of the industrial psychologist could be explored.

This purposeful choice of business frameworks was done in accordance with the accepted view that data for qualitative, grounded theory research can be selected precisely because it is thought to be useful in furthering understanding of a specific area of focus (Neuendorf, 2002; Schwandt, 2001; Uys \& Puttergill, 2000; Willig, 2001) and because it would possibly demonstrate manifestations of the phenomenon of interest (Schwandt, 2001). To better understand the process of data analysis a brief description of the three chosen business frameworks is provided below.

\section{Balanced Scorecard}

Traditionally, organisations relied on financial indicators or measures to determine organisational performance. Kaplan and Norton (1996) believed that this approach was becoming obsolete and subsequently created the Balanced Scorecard which reflects a balance between short and long-term objectives, financial and non-financial measures, lagging and leading indicators, and external and internal performance perspectives. They defined the Balanced Scorecard as a framework that helps organisations translate strategy into operational objectives that drive both behaviour and performance. Hepworth (1998) argued that the success of the Balanced Scorecard was "to be derived from a comprehensive visibility of all the key business areas and identifying and exploiting the linkages that deliver success" (p. 560). The four key focus areas are the financial perspective, customer perspective, internal perspective and learning and growth perspective.

According to Kaplan and Norton (1996) the financial perspective includes financial performance measures that "indicate whether a company's strategy, implementation and execution are contributing to bottom-line improvement. Financial objectives typically relate to profitability - measured, for example, by operating income, return-on-capital-employed, or more recently, economic value-added" (p. 26). Alternative financial objectives can be rapid sales growth or generation of cash flow. The customer perspective, according to Kaplan and Norton (1996) refers to "the customer and market segments in which the business unit will compete and the measures of the business unit's performance in these targeted segments. The core outcome measures include customer satisfaction, customer retention and new customer acquisition" (p. 26). From an internal perspective, in the third place:

“... executives identify the critical internal processes in which the organization must excel. These processes enable the business unit to deliver the value propositions that will attract and retain customers in targeted market segments and to satisfy shareholder expectations of excellent financial returns. The internal-business-process measures, therefore, focus on the internal processes that will have the greatest impact on customer satisfaction and on achieving an organization's financial objectives" (Kaplan \& Norton, 1996, p. 26).

Lastly, from a learning and growth perspective, the Balanced Scorecard places emphasis on the necessity to "build and create long-term growth and improvement namely people, systems and organizational procedures" (Kaplan \& Norton, 1996, p. 28). Essentially, the Balanced Scorecard translates vision and strategy into objectives and measures across a balanced set of perspectives. The scorecard includes measures of desired outcomes as well as processes that will drive the desired outcomes for the future (Kaplan \& Norton, 1996, p. 10). The Balanced Scorecard is graphically depicted in Figure 1.

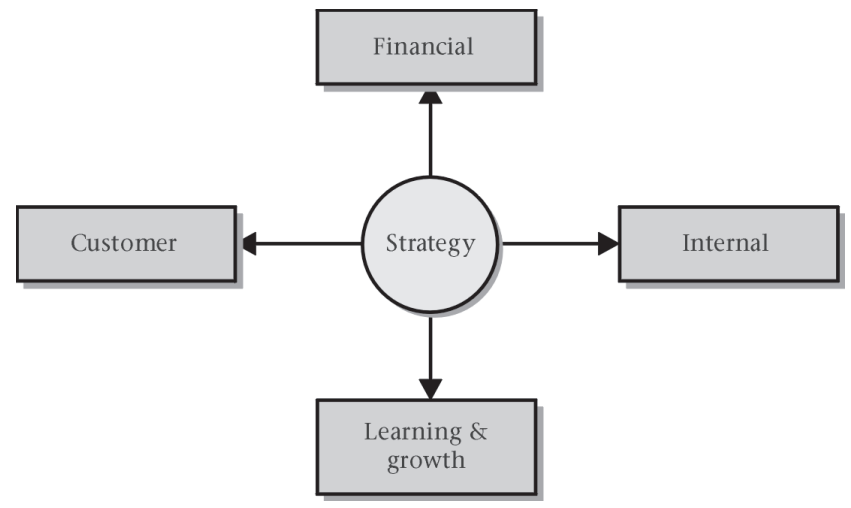

Figure 1: Balanced Scorecard (Olve, Roy \& Wetter, 2000, p. 147) 
It is assumed that organisational success can be enhanced by performance in all four these areas where each is afforded due attention in its own right.

\section{South African Excellence Model}

The South African Excellence Model is a framework based on Total Quality Management principles. It aims to assist organisations to achieve excellence through continuous improvement in the management and deployment of processes to engender wider use of best practice activities. It enables the calculation of scores against a number of criteria that can be used for either internal or external benchmarking. Comparisons lead to increased focus on improving the performance of key performance processes and ultimate excellence (South African Excellence Foundation, 1997).

The South African Excellence Model is divided into two main criterion groupings, namely enablers and results. These criteria have various sub-criteria to ensure overall organisational effectiveness and enhanced performance. Van der Watt, Van Wijck and Von Benecke (2001) suggested that this logical approach would enable management to easily determine shortcomings, address them systematically, implement the most feasible options effectively and evaluate their performance objectively. The South African Excellence Model enabler criteria are defined as Leadership (how the behaviour and the actions of the executive team and all other leaders inspire, support and promote a culture of performance excellence), Policy and strategy (how the organisation formulates, deploys, reviews and turns policy and strategy into plans and actions), Customer and market/shareholder focus (how the organisation determines the needs, requirements and expectations of the market, enhances relationships, and determines satisfaction of customers and markets), People management (how the organisation develops and releases the full potential of its people), Resource and information management (how the organisation manages and uses resources and information effectively and efficiently) and Processes (how the organisation identifies, manages, reviews and improves its processes).

The South African Excellence Model results criteria are defined as Impact on society (what the organisation is achieving in satisfying the needs and the expectations of the local, national and international community at large), Customer/stakeholder satisfaction (what the organisation is achieving in relation to the satisfaction of its external customers), People satisfaction (what the organisation is achieving in relation to the satisfaction of its people), Supplier and partnership performance (what the organisation is achieving in relation to the management of supplier and partnering processes), and Organisational results (what the organisation is achieving in relation to its planned business objectives and in satisfying the needs and expectations of everyone with a financial interest or other stake in the organisation). Figure 2 graphically depicts the South African Excellence Model.

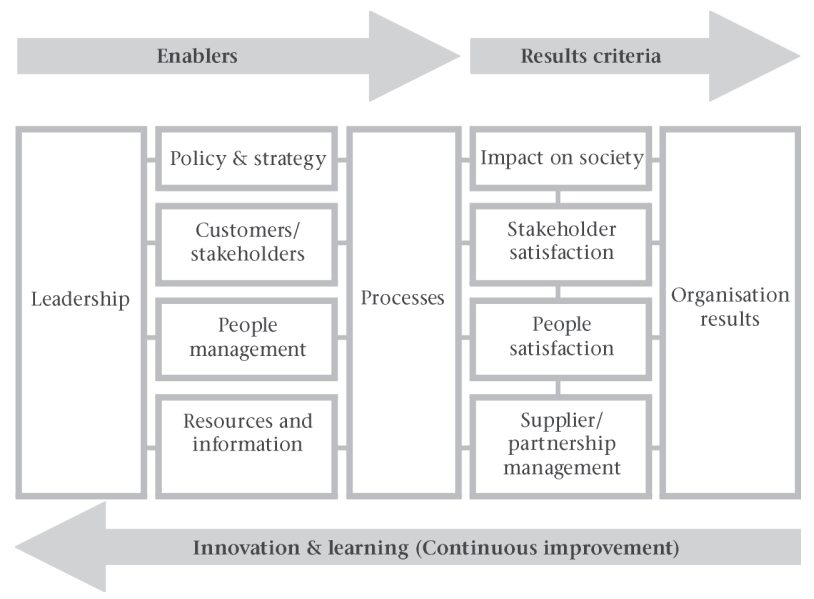

Figure 2: The South African Excellence Model (South African Excellence Foundation, 1997, p. 6)
The South African Excellence Model represents the notion that organisational success can be enhanced by continuously striving to perform against both the enabler and the results criteria of the conceptual model.

King II Report on Corporate Governance for South Africa (Institute of Directors, 2002)

Apart from complying with a myriad of legislation, listed organisations on the South African Stock Exchange (JSE) must generally also adhere to principles of good corporate governance. In 1994 the King Committee on Corporate Governance published the Report on Corporate Governance (King I), incorporating a Code of Good Corporate Practices and Conduct aimed at uplifting and enhancing the standards of corporate governance in South Africa. The evolving global economic environment necessitated the revision of the King I Report and subsequently, in 2002, the King Committee developed the King II Report on Corporate Governance for South Africa (Institute of Directors, 2002). This report advocated a move away from the single bottom line criterion for company performance towards a so-called triple bottom line criterion that embraces the economic, environmental and social aspects of a company's activities. Although not all organisations are required to adhere to the provisions of the King I and King II Report on Corporate Governance for South Africa, most organisations do have some policy on good governance, be it formalised or non-formalised (Institute of Directors, 2002). Seven criteria for good corporate governance are proposed in these reports. These criteria are briefly described below:

Discipline (that implies a commitment to proper behaviour and to the underlying principles of good governance), Transparency (that refers to the ease with which an outsider can analyse the company in terms of financial and non-financial aspects of the organisation), Independence (that refers to mechanisms to prevent conflicts of interest such as dominance by a strong chief executive or large shareholder), Accountability (according to which decision-makers in organisations must be accountable for decisions and actions), Responsibility (that refers to behaviour that allows for corrective action and for penalising mismanagement), Fairness (the systems that exist within an organisation which must be balanced in taking into account all those that have an interest in the organisation and its future) and Social responsibility (that refers to the awareness and response to social issues and placing a high priority on ethical standards).

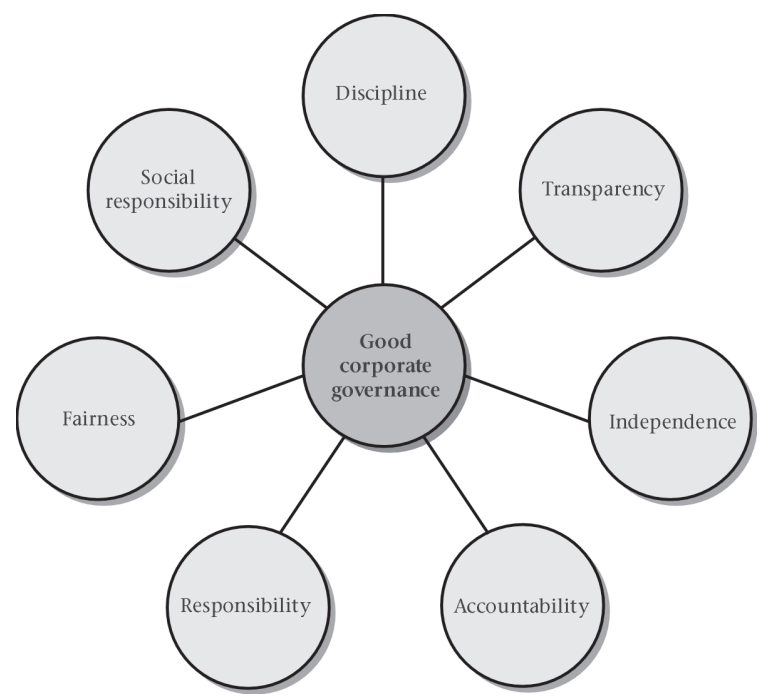

Figure 3: Seven characteristics of Good Corporate Governance (Institute of Directors, 2002)

Figure 3 graphically depicts the key performance criteria of the King II Report on Corporate Governance for South Africa. It is assumed that organisations that adhere to these criteria will 
enhance their success and at the same time comply with global expectations for good corporate governance.

The brief discussion provided above possibly does not give due credit to the sophisticated nature of the three business frameworks in their own right and probably disregards the complexity of the thinking that went into the development of each. For purposes of the development of the integrated framework proposed in this study, however, an in-depth and reflective exploration of the different frameworks was undertaken to gain a deeper understanding of the similarities, differences and unique contributions of each.

\section{Data analysis}

Available literature on the three business frameworks were analysed in an attempt to capture the inherent intent, clearly identified themes of focus, and performance-referenced criteria of each. A systematic content-analytic process was followed firstly to identify key as well as supportive theoretical themes from each of the models and secondly, to integrate these into a single coherent framework to retain meaningful input from each. Although the Balanced Scorecard, South African Excellence Model and King 11 Report on Corporate Governance for South Africa were developed independently from one another, a great degree of overlap appeared to exist within each of these frameworks in terms of the underlying themes or dimensions (criteria) regarded as relevant and important for organisational success and sustainability, for example: The Balanced Scorecard's Financial Perspective could be related to the Organisational Results criterion of the South African Excellence Model, both dealing with tangible financial results in terms of an organisation's performance. In similar vein the Balanced Scorecard's Customer Perspective could be related to the South African Excellence Model's Customer and Stakeholder Focus, both aiming at improving customer and stakeholder relations. With reference to the Internal Perspective of the Balanced Scorecard it could be related to the Processes criterion of the South African Excellence Model, both focussing on the continuous improvement of those processes that generate the right form of value for customers. Similarly, the Balanced Scorecard's Learning and Growth Perspective could be related to the South African Excellence Model's People Management and People Satisfaction criteria, and the South African Excellence Model's Impact on Society criterion could be related to the Social Responsibility criterion of the King II Report on Corporate Governance for South Africa.

By systematically analysing the three business frameworks on the basis of their inherent intent and clearly identified themes of focus as illustrated above, 22 dimensions/performancereferenced criteria were derived. By matching and grouping the same or similar criteria together these were subsequently reduced to 14 dimensions/performance-referenced criteria. For example, by matching the Internal Perspective of the Balanced Scorecard with that of the Processes criterion of the South African Excellence Model and by grouping them into one category, an Internal Systems and Processes dimension was created. This process of analysis and reduction was followed to reduce the complexity of any future analyses and to avoid unnecessary duplication of themes and criterion elements. Within each of the dimensions described above, a limited number of operational criteria that were implied during the process of thematic content analysis were captured to broadly illustrate the nature and scope of the criterion domain. These operational criteria were in no way intended to fully describe and delineate the domain, but to provide a broad framework to direct subsequent thinking and exploration.

The integration of the frameworks implied above, primarily on the basis of common and recurring themes whilst simultaneously incorporating unique contributions from each, obviously required a large degree of interpretation and creative thinking on the part of the researchers. This, however, as explained earlier, was deemed acceptable within a qualitative research approach (Gergen \& Gergen, 2003; Mauer, 1996; Wolcott, 2001) and as part of the exploratory phase of the process aimed at the development of a framework of thought (working hypothesis) against which further empirical research could be undertaken.

\section{FINDINGS}

The following dimensions of organisational functioning perceived to be crucial to organisational success and survival were identified through the process: (1) Long-term sustainability of the organisation, (2) Governance and ethics, (3) Financial well-being of the organisation, (4) Strategic positioning, vision and mission, (5) Strategies, (6) Organisational structure, (7) Internal systems and processes, (8) Leadership, (9) Human capital management, (10) Building core organisational capabilities, (11) Creativity, innovation and change, (12) Organisational identity, culture, values and wellness, (13) Customers and other stakeholders and (14) Corporate social responsibility. At this point it was proposed that performance in each of these dimensions would ensure organisational well-being and success, and that it would be sensible for industrial psychologists to define their role and contributions to organisations within these. A fifteenth dimension namely (15) Ergonomics was deliberately added. Although it could be argued that Ergonomics can be included in the Internal Perspective of the Balanced Scorecard and the Processes criterion of the South African Excellence Model, the link was not that obvious. Ergonomics was added on the basis that it currently forms part of the academic framework of $\mathrm{I} / \mathrm{O}$ Psychology at some universities in South Africa and as such, is still recognised as a sub-discipline of the academic field. The addition of Ergonomics to the proposed multi-dimensional conceptual framework was a deliberate attempt to assess the degree to which practising industrial psychologists perceive it to be part of the day-to-day focus of their profession. Finally, a sixteenth dimension, (16) Other areas of influence (General), was added to make provision for any other areas of influence that might not have been covered by the 15 dimensions discussed earlier, but are nevertheless recognised by practising industrial psychologists as part of their field.

A critical reflection on the relationships between the 14 initial dimensions identified above highlighted a noteworthy feature from the data. Whereas the Balanced Scorecard represented a strong internal focus, a so-called single bottom-line approach primarily focused on shareholder concerns and interests, a people-focus not uniquely defined, and a limited external focus essentially extending towards customers, the South African Excellence Model presented a somewhat wider-reaching area of concern. The latter extended its financial focus to incorporate the interests of everyone with a financial or other stakeholder concern. It furthermore presented a much stronger emphasis on leadership, people management and people satisfaction criteria. In addition, it included suppliers, other partners, other stakeholders as well as the broader society in its externally-focused results criteria. The King II Report on Corporate Governance for South Africa, on its part, extended this external focus even further to accommodate the notion of broad-based social responsibility. This included a so-called triple-line performance criterion that incorporated financial, economic, social and environmental performance indicators. It furthermore introduced the notion of sound corporate governance, implying an assessment not only of what an organisation had achieved but how it achieved these objectives. This criterion would partially reflect the organisation's identity, character, values, principles and ethical guidelines for action. The above feature appears to indicate an appreciation for the ever wider-reaching impact of organisational action and along with it, an ever wider-stretching domain within which performance criteria arguably have to be developed. This line of thinking is embodied in Figure 4. 


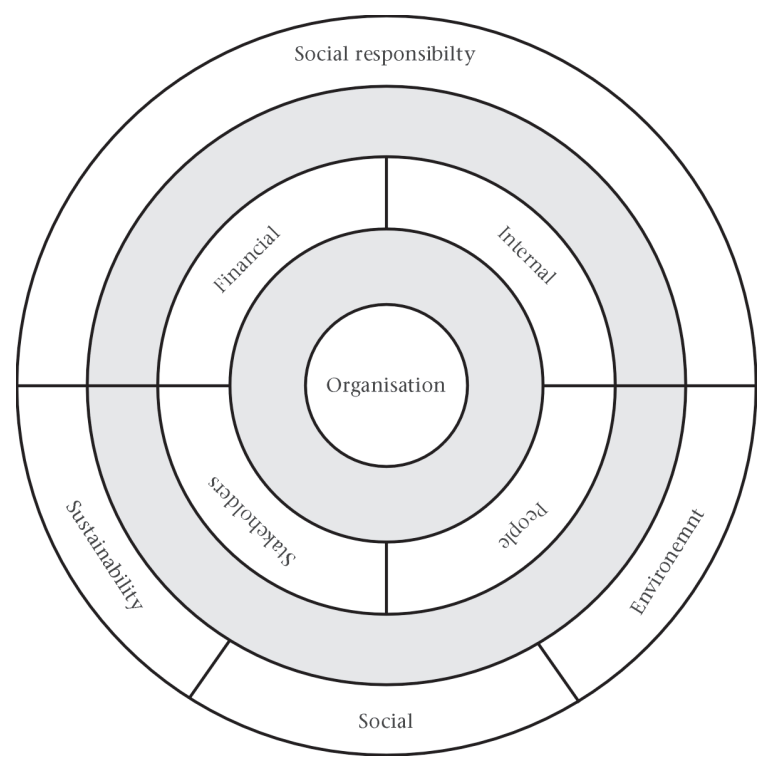

Figure 4: Key dimensions of organisational functioning and success

Figure 4 illustrates the conceptual framework that evolved from a multi-dimensional perspective on the key dimensions of organisational functioning and success implied by the three business frameworks analysed above. Performance in each of the identified dimensions is perceived to be of crucial importance in directing and assessing organisational success and sustainability, broadly speaking. According to this view, an organisation's success and sustainability will be influenced by (1) it's inherent character and by the way it does business, (2) by its actual performance in four specific domains - financial, internal processes and systems, people and immediate stakeholders - and (3), by its ability to show social responsibility in a wider sense, taking into account economic, social and environmental concerns.

\section{DISCUSSION}

To facilitate a common understanding of the multi-dimensional conceptual framework outlined above, each of the dimensions is briefly discussed in the next section. Whilst the intention was not to develop a comprehensive description of each of these dimensions in the exploratory stages of this study, broad trains of thought pertaining to each are nevertheless highlighted to facilitate mutual understanding among participants in the intended future stages of the research. These dimensions are deliberately discussed in random order to allow for a minimum degree of prior categorisation and sorting of any research input in future.

\section{Long-term sustainability of the organisation}

This dimension was intended to capture the criteria broadly related to the organisation's ability to remain relevant, grow and survive.

\section{Governance and ethics}

The King II Report on Corporate Governance for South Africa (Institute of Directors, 2002, p. 19) stated that:

...successful governance in the world of the $21^{\text {st }}$ century requires companies to adopt an inclusive and not exclusive approach. The company must be open to institutional activism and there must be greater emphasis on the sustainable or non-financial aspects of its performance. Boards must apply the test of fairness, accountability, responsibility and transparency to all aspects or omissions and be accountable to the company but also responsive and responsible towards the company's identified stakeholders. The correct balance between conformance with governance principles and performance in an entrepreneurial market economy must be found, but this will be specific to each company.

From a similar perspective the Ethics Institute of South Africa (n.d.) referred to ethical and mutually beneficial behaviour on the part of the organisation and defined ethics in this sense as:

The discipline of critical reflection on the nature of morality; a systematic endeavour to understand the values and principles informing right, good and fair individual human actions (conduct) and collective human actions in institutions (practices), as well as the good society. Conduct and practices conforming to these standards are judged to be ethical; conversely, those that do not are judged to be unethical.

This implies that organisations must engage in acts of good corporate governance complemented by ethical behaviour in order to ultimately enhance both its financial and non-financial performance.

\section{Financial well-being of the organisation}

Financial well-being has been and will probably always be one of the major driving forces and assessment criteria in both profit and non-profit organisations. Kaplan and Norton (1996) acknowledged the importance of the financial well-being of organisations by including it as one of the four perspectives of their Balanced Scorecard whereas financial well-being and sustainability are also highlighted in terms of the Results criterion of the South African Excellence Model. Even the King II Report on Corporate Governance for South Africa acknowledges the legitimate aim of business to make a reasonable profit.

\section{Strategic positioning, vision and mission}

This dimension was intended to capture the essence of sound strategic management that aims to clearly define an organisation's vision and mission and then strategically position the organisation to achieve its objectives. It is generally suggested that such a strategic management approach utilises processes such as environmental scanning, scenario planning, strategic planning and assessment of results (Fahey, 2003; Lamotte in Anderson, Lawrie \& Shulver, 2000).

\section{Strategies}

Literature abounds with definitions of strategy. Although it is valuable to have consensus on the definition of strategy, it is perhaps more important to focus on the way in which strategy is actually executed. According to Fortune Magazine only ten percent of effectively formulated strategies are executed effectively (Norton, 2003). The concept of a strategy-focused organisation, as coined by Kaplan and Norton (2001), emanated from the perceived lack of strategic focus in organisations. Kaplan and Norton's (2001) notion of strategy-focused organisations involves translating strategy into operational terms, aligning these to create synergies and mobilising change through executive leadership. It can thus be deduced that strategy is a process with logical and sequential steps that will enable an organisation to reach it strategic objectives.

\section{Organisational structure}

Ivancevich and Matteson (1996) argued that organisational structure and design have always played an important role in influencing the behaviour of individuals and groups within organisations. The information age has brought with it a range of dynamics that includes, amongst others, virtual places of work and flattened organisational structures that pose unique challenges in terms of structure and behaviour within organisations. To this end the traditional 'shopping lists' of organisational structural design models are becoming superfluous. In developing countries, such as South Africa, where the world of work stretches on a continuum from basic manual labour to technologically advanced virtual offices, the challenge probably is to cater for all models of organisational structural design to best suit the characteristics and needs of the organisation and its people. 


\section{Internal systems and processes}

Internal systems and processes are those activities within an organisation that ensure and enhance performance. The Balanced Scorecard's Internal Perspective deals specifically with internal systems and processes which play a significant role in the cause-and-effect relationship within and between the different internal perspectives (Kaplan \& Norton, 1996).

In terms of the South African Excellence Model it is important to focus on the impact of key and support processes on the organisation and to design production and delivery processes that will meet quality and operational requirements. The systematic management of processes includes the establishment of process ownership, process management, responsibility and accountability. Processes must also be reviewed on a continuous basis and targets must be set for the improvement thereof by making use of innovation and creativity (South African Excellence Foundation, 1997).

\section{Leadership}

Rhinesmith in Prinsloo, Moropodi, Slabbert and Parker (1999) argued that leadership is about creating the conditions where people can perform to their potential in a fashion in which they and the organisation are comfortable. Hesselbein, Goldsmith and Beckhard (1998) speculated on the nature of leadership in future and suggested that (1) leadership will reside less at the top and rather be shared throughout an organisation, (2) charismatic leaders will be less important than the processes the leaders create, (3) individual leadership will be replaced by team leadership, (4) the new leader will be more likely to ask questions than to give answers, (5) leaders will be less likely to look for and accept simple solutions and more likely to identify and live with paradoxes, (6) focus will shift from reliance on purely analytical tools in favour of integration of the analytical and the affective, (7) global thinking and demeanour will replace an exclusively domestic focus and (8) interest in questions and learning will replace focus on solutions and answers.

Kaplan and Norton (2004) addressed the issue of leadership in the Learning and Growth perspective of the Balanced Scorecard and referred specifically to the ability of the organisation to mobilise and sustain the process of change required to execute the strategy. Leadership is also a very important criterion within the South African Excellence Model and refers specifically to how the behaviour and the actions of the executive team and all other leaders inspire, support and promote a culture of performance excellence. This includes, amongst others, how leaders support improvement and involvement by providing appropriate resources and assistance, how leaders are involved with customers, partners and supplier chains, how leaders recognise and appreciate people's efforts and achievements, and how leaders address public responsibilities and practice good citizenship (South African Excellence Foundation, 1997).

\section{Human capital management}

Pfau and Kay (2002) identified four human capital practices that have a positive impact on the bottom line: Achieving recruiting and retention excellence, creating a total reward and accountability orientation, establishing a collegial workplace, and opening up communication between management and employees. This approach to human capital management is echoed in the South African Excellence Model's People Management criterion which focuses on the improvement of human resource planning, maintenance and development, performance improvement, empowerment, enablement and recognition, and effective dialogue of people in the organisation.

The Balanced Scorecard deals with human capital management under the Learning and Growth Perspective. Kaplan and Norton (1996) identified three core employee measurements: employee satisfaction, employee retention and employee productivity. Measuring employee satisfaction specifically deals with elements such as employee involvement in decision-making, recognition of exceptional performance, access to sufficient information to do the job well, as well as active encouragement to be creative and to use initiative. Measuring employee retention involves the long-term investments organisations make in people to prevent the unwanted loss of personnel representing the intellectual capital of the organisation. Kaplan and Norton (1996) argued that employee productivity is "an outcome measure from the aggregate impact from enhancing employee skills and morale, innovation, improving internal processes, and satisfying customers."

The King II Report on Corporate Governance for South Africa, on its part, stated that human capital denotes the latent or potential value that employees at all levels, individually or collectively, represent for an organisation. The ongoing challenge is for organisations to benefit from and to capitalise on this latent potential, which can be achieved through effective training, development and knowledge management processes which will be reflected in good management practices such as succession planning. The nurturing, protecting, capturing, retaining and developing of human capital as vital ingredients for sustainable economic performance for organisations and society at large are therefore perceived to be crucial (Institute of Directors, 2002).

\section{Building core organisational capabilities}

Hayes and Pisano (in Swink \& Hegarty, 1998, p. 374) defined core organisational capabilities as those activities a firm can do better than its competitors. They continued by stating "a capability is not something a firm can buy. Capabilities are organizationally specific; they must be developed internally. The fact that they are difficult to imitate or transfer is what makes them valuable". It can be argued, therefore, that core organisational capabilities are derived from people, management, information systems, learning and an organisation's goal focus.

Building core organisational capabilities is addressed in the Balanced Scorecard in the Learning and Growth Perspective under the heading: Human Capital. Human Capital in the Balanced Scorecard deals specifically with employee skills, training and knowledge and the fundamental aspects necessary for building core organisational capabilities (Kaplan \& Norton, 2004). The South African Excellence Model addresses the building of core organisational capabilities within the People Management criterion which focuses on how people capabilities are sustained and developed by, amongst others, the establishment and implementation of education and training programmes, the development of people through work experience, the promotion of continuous learning, and the adoption of an innovative approach to adult education and training (South African Excellence Foundation, 1997). It has to be appreciated that the notion of core capabilities of an organisation goes beyond that of talent management only, to essentially refer to an integrated organisational capacity (relating to people, systems, processes, knowledge, innovation, creativity and learning) that ultimately ensures the organisation's competitive advantage.

\section{Creativity, innovation and change}

The Balanced Scorecard and the South African Excellence Model are both frameworks based on the principle of continuous improvement by advocating and promoting creativity, innovation and change (Kaplan \& Norton, 1996; South African Excellence Foundation, 1997). Whilst creativity is primarily viewed as some special inspiration (Henry, 2002), it is nevertheless seen as intrinsic and essential to life and growth. Innovation, on the other hand, is often viewed as a process and not so much as a single event (Cooper, 1998). Proponents of the process definition of innovation are primarily concerned with the role of communication in facilitating successful innovation, best practices in terms of sequencing the stages of innovation, the characteristics of individuals and teams in successful and unsuccessful processes, and the nature of the relationship of the parties involved in the innovation. The proponents of innovation propose that innovation takes place when there is actual 
acceptance of risk and commitment of resources. Regardless of the ongoing debate of what constitutes innovation, practitioners and students of innovation widely agree that innovation comes in many forms. Of even greater importance is what factors would enhance the propensity for innovation, such as organisational structures and design, strategy and power (Cooper, 1998). It is up to organisations, therefore, to determine the 'perfect mix' so as to enhance the propensity of innovation.

With reference to the concept of change, Ulrich (1997) regarded adjusting to change as the greatest challenge organisations face. He added that organisations must be able to learn rapidly and continuously, innovate ceaselessly, and take on new strategic imperatives faster and more comfortably. It is also necessary for organisations to challenge the status quo, make rapid decisions, and to have the agility to change the way they are doing business. Therefore, according to Ulrich (1997), organisations need to be in a never-ending state of enduring change if they were to thrive and survive.

\section{Organisational identity, culture, values and wellness}

The concept of corporate identity evolved through the years, gradually broadened, and is now taken to indicate the way in which an organisation's identity is revealed through symbolism, communications and behaviour. In realising the difficulty in defining corporate identity, the International Corporate Identity Groups (ICIG) made a statement on corporate identity (Van Riel \& Balmer, 1997, p. 355):

Every organisation has an identity. It articulates the corporate ethos, aims and values, and presents a sense of individuality that can help to differentiate the organisation within its competitive environment. When well managed, corporate identity can be a powerful means of integrating the many disciplines and activities essential to an organisation's success. It can also provide the visual cohesion necessary to ensure that all corporate communications are coherent with each other and result in an image consistent with the organisation's defining ethos and character. By effectively managing its corporate identity an organisation can build understanding and commitment among its diverse stakeholders. This can be manifested in an ability to attract and retain customers and employees, achieve strategic alliances, gain the support of financial markets, and generate a sense of direction and purpose. Corporate identity is a strategic issue. Corporate identity differs from traditional brand marketing since it is concerned with all of an organisation's stakeholders and the multi-faceted way in which an organisation communicates.

Closely related to the concept organisational identity is that of organisational culture. Organisational culture describes the part of an organisation's internal environment that incorporates a set of assumptions, beliefs and values that organisational members share and use to guide their functioning (Gordon, 1996). Organisational culture encompasses the values, norms, behaviour, systems as well as policies and procedures through which an organisation adapts to the complexity of the global arena (Rhinesmith, 1996). Values are an organisation's basic precept about its view of humanity, its role in society, what is important in both business and in life, how business should be conducted, the way the world works, and what is to be held inviolate (Prinsloo et al., 1999). Core values are believed to be a business organisation's most essential and enduring tenet that has intrinsic value and importance to all employees (Prinsloo et al., 1999). Rhinesmith (1996) argued that one of the greatest challenges of organisations is to align their corporate culture and people with their strategies and structures. Corporate wellness refers to the adoption of long-term organisational practices and personal behaviour conducive to maintaining and improving employees' physiological, mental and social wellbeing, to increase productivity and to enhance the corporate image of the organisation (Ho, 1997). Albeit poorly appreciated as yet, organisational identity, its culture, its values and its state of wellness will arguably be increasingly influential in determining success, growth and ultimate sustainability of any organisation.

\section{Customers and other stakeholders}

Customers are probably the most important stakeholders of any organisation. It is thus not surprising that such a huge amount of attention has been paid to customers and other stakeholders, both in literature and at a practical level in organisations (profitable, non-profit and governmental). This lead to the development of so-called customer-centred strategies which aim to satisfy the needs and expectations of customers and stakeholders by ensuring that performance and business results are as good, or better than, the best of the competition (Prescott, 1998).

The Customer Perspective of the Balanced Scorecard enables the organisations to align their core customer outcome measures, namely satisfaction, loyalty (market share), retention, acquisition and profitability to targeted customers and market segments (Kaplan \& Norton, 1996). These criteria are briefly defined below. Customer satisfaction assesses the satisfaction level of customers along specific performance criteria. Market share reflects the proportion of business in a given market (in terms of the number of customers, money spent, or unit volume sold). Customer retention tracks the rate at which a business unit retains or maintains ongoing relationships with its customers. Customer acquisition measures the rate at which a business unit attracts or wins new customers or business. Customer profitability measures the net profit of a customer or a segment, after allowing for the unique expenses required to support that customer.

In addition to the above core outcome measurements, organisations must also identify what customers in targeted segments value and select the value proposition it will deliver to these customers. This selection can be made from three classes of attributes: product and service attributes (functionality, quality and price), customer relationship attributes (quality of purchasing experience and personal relationships), and attributes related to image and reputation. By selecting specific objectives and measures across these three classes, organisations can focus on delivering a superior value proposition to their targeted customer segments (Kaplan \& Norton, 1996).

The South African Excellence Model highlights the Customer and Stakeholder Focus as one of its enabling criteria and Customer Satisfaction as one of its results criteria. The South African Excellence Model describes the customer and stakeholder focus as the way in which the organisation determines the needs, requirements and expectations of its customers, enhances relationships, and determines satisfaction of customers and stakeholders. Customer satisfaction is defined as what the organisation is achieving in relation to the satisfaction of its external customers (South African Excellence Foundation, 1997).

\section{Corporate social responsibility}

The King II Report on Corporate Governance for South Africa highlights the importance and benefits of being socially responsible. It argues that an organisation is likely to experience indirect economic benefits, such as improved productivity and corporate reputation, by placing a high priority on social issues and ethical standards (Institute of Directors, 2002). The South African Excellence Model also deals with the Impact on Society as one of its results criteria. It defined impact on society as that which the organisation is achieving in satisfying the needs and expectations of the local, national and international community at large. This includes the perception of the organisation's approach to quality of life, the environment and conservation of global resources, the organisation's own internal measures of effectiveness, and its relations with other authorities and bodies that affect and regulate its business (South African Excellence Foundation, 1997). 


\section{Ergonomics}

The word ergonomics is derived from the Greek words 'ergo' and 'nomos', meaning 'work' and 'natural laws' respectively, hence ergonomics literally means the laws of work (Sluchak, 1992, p.107). Although there is no consensus in the literature on the definition of ergonomics, the most common view is that ergonomics encompasses the relationship between humans, machine systems, job design and the work environment. Thus, the ultimate goal of ergonomics is to enable workers to be more effective and efficient by matching the requirements and the demands of the job to the abilities and limitations of workers, rather than trying to force the workers to fit the job (Rowan \& Wright, 1995, p. 24). Ergonomics draws its knowledge from various fields in the human sciences and technology, including anthropometrics, biomechanics, physiology, psychology, toxicology, mechanical engineering, industrial design, information technology and industrial management. Ergonomics has an interdisciplinary and applied nature since it relates to many different human facets. The ultimate aim of Ergonomics is to adapt the workplace or environment to people and not vice versa (Dul \& Weerdmeester, 1994, p. 2).

Rowan and Wright (1995) highlighted the growing interest in ergonomics from perspectives such as the increasing costs (both direct and indirect) associated with work-related injuries and diseases, compliance with labour legislation which provides for reasonable accommodation to allow disabled workers the opportunity to work, the cost of absenteeism, restricted work-day cases, turnover and retraining. Good ergonomics management promotes improved quality, productivity, efficiency, employee morale, job satisfaction and loyalty.

The placement of ergonomics within a specific field of study has always been a point of debate. In this respect Ahasan and Imbeau (2003) stated that "[t]he field of ergonomics is sometimes a battlefield (or at least a sparring ring) between rival professional groups who all want to partition ergonomics and claim all or part of it for themselves". Despite the fact that a clear link between Ergonomics and the three frameworks within the triad-framework discussed earlier could not be established, it was nevertheless included as one of the dimensions of the multi-dimensional conceptual framework. It was expected that the second part of the study would cast light on this unclear role and discipline-specific distinctions, if any.

\section{Other areas of influence (general)}

This dimension was included to cover all those areas of influence or importance that might have been overlooked in the development of the 15 dimensions mentioned above. As a final result, Table 1 represents a randomly organised presentation of the sixteen dimensions of the proposed conceptual framework - including the limited number of operational criteria that were implied during the process of thematic content analysis - broadly illustrating the nature and scope of the criterion domain. This random organising was again deliberately done to limit researcher influence on the data gathering and data analysing processes envisaged in future stages of the research.

It was envisaged that, if adapted and validated through further research, the framework presented in Table 1 could be used by an organisation to assess its performance in each of the sixteen dimensions and by so doing, form an overall impression of its sustainability, wellness and growth. In similar vein it was hypothesised that if industrial psychologists could clarify, qualify and quantify their roles and contributions within each of these domains it would ensure that they make valuable inputs that will at the same time be more recognisable and possibly better appreciated by other stakeholders. It was believed that industrial psychologists could, for example, ask what their role and contributions were towards ensuring the relevance, growth and survival of the organisation (Long-term sustainability of the organisation) or similarly towards establishing clarity of purpose,

TABLE 1

MULTI-DIMENSIONAL CONCEPTUAL FRAMEWORK TO EXPLORE THE ROLES AND CONTRIBUTIONS OF INDUSTRIAL PSYCHOLOGISTS

\begin{tabular}{|c|c|c|c|}
\hline $\begin{array}{l}\text { Long-term Sustainability of the } \\
\text { Organisation }\end{array}$ & Governance and Ethics & $\begin{array}{l}\text { Financial } \\
\text { Well-Being of the Organisation }\end{array}$ & $\begin{array}{l}\text { Strategic positioning, Vision and } \\
\text { Mission }\end{array}$ \\
\hline $\begin{array}{ll}\text { - } & \text { Relevance } \\
\text { - } & \text { Growth } \\
\text { - } & \text { Survival }\end{array}$ & $\begin{array}{ll}\text { - } & \text { Fairness } \\
\text { - } & \text { Transparency } \\
\text { - } & \text { Sound governance } \\
\text { - } & \text { Ethical decisions } \\
\text { - } & \text { Triple-bottom line }\end{array}$ & $\begin{array}{l}\text { - } \text { Short-term financial health } \\
\text { - } \text { Reasonable profit } \\
\text { - } \text { Effectiveness } \\
\text { - } \text { Competitiveness }\end{array}$ & $\begin{array}{ll}\cdot & \text { Clarity of purpose } \\
\cdot & \text { Goal-directedness } \\
\cdot & \text { Support and buy-in }\end{array}$ \\
\hline Strategies & Organisational Structure & Internal Systems and Processes & Leadership \\
\hline $\begin{array}{ll}\text { - } & \text { Defined strategies } \\
\text { - } & \text { Adequate resources } \\
\text { - } & \text { Mear targets } \\
& \text { Mearable outcomes }\end{array}$ & $\begin{array}{ll}\cdot & \text { Structure supportive of } \\
\cdot & \text { strategies } \\
\cdot & \text { Lean } \\
\cdot & \text { Adequate } \\
\cdot & \text { Effective }\end{array}$ & $\begin{array}{ll}\cdot & \text { Efficient } \\
\cdot & \text { In time } \\
\cdot & \text { Optimally functional } \\
\cdot & \text { Supportive of other objectives } \\
& \text { (e.g. customer satisfaction) }\end{array}$ & $\begin{array}{ll}\cdot & \text { Available } \\
\cdot & \text { Empowered } \\
\cdot & \text { Competent } \\
\cdot & \text { Dynamic } \\
\cdot & \text { Visionary } \\
\cdot & \text { Leading } \\
\cdot & \text { Ethical }\end{array}$ \\
\hline Human Capital Management & $\begin{array}{l}\text { Building Core Organisational } \\
\text { Capabilities }\end{array}$ & Creativity, Innovation \& Change & $\begin{array}{l}\text { Corporate Identity, Culture, Values } \\
\text { and Wellness }\end{array}$ \\
\hline $\begin{array}{ll}\cdot & \text { Needs being met } \\
\cdot & \text { Quantified } \\
\cdot & \text { Valued as an asset } \\
\cdot & \text { Maintained } \\
\cdot & \text { Developed } \\
\cdot & \text { Optimally utilised } \\
\cdot & \text { Nurtured } \\
\cdot & \text { Retained } \\
\text { - } & \text { Employer of choice }\end{array}$ & $\begin{array}{ll}\cdot & \text { Integrated capacity } \\
\cdot & \text { People } \\
\cdot & \text { Management } \\
\cdot & \text { Systems } \\
\cdot & \text { Information } \\
\cdot & \text { Knowledge } \\
\cdot & \text { Unique capabilities }\end{array}$ & $\begin{array}{ll}\cdot & \text { Adaptable } \\
\cdot & \text { Reasonably risk-prepared } \\
\cdot & \text { Creative } \\
\cdot & \text { Novel solutions }\end{array}$ & $\begin{array}{ll}\cdot & \text { Internalised organisational character } \\
\text { - } & \text { Clear and defining values } \\
\text { - } & \text { Organisational health and wellness }\end{array}$ \\
\hline Customers and Other Stakeholders & Corporate Social Responsibility & Ergonomics & Other areas of Influence \\
\hline $\begin{array}{ll}\cdot & \text { Stakeholder engagement } \\
\text { - } & \text { Reputation } \\
\text { - } & \text { Respect } \\
\text { - } & \text { Credibility } \\
\text { - } & \text { Satisfaction } \\
\text { - } & \text { Preferred choice }\end{array}$ & $\begin{array}{l}\text { - Awareness of impact on others } \\
\text { - Meaningful contribution towards } \\
\text { larger goals }\end{array}$ & $\begin{array}{l}\text { Optimisation of man/machine } \\
\text { interface } \\
\text { - Occupational health and safety }\end{array}$ & \\
\hline
\end{tabular}


goal-directedness and buy-in for the organisation's vision and mission (Strategic positioning, vision and mission). They could assess their role and contributions in ensuring that organisational structures were lean, adequate, effective and supportive of the organisation's strategies (Organisational Structures) and they could reflect on their involvement in creating a context that is adaptable, reasonably risk-prepared, creative and open to novel solutions (Creativity, Innovation and Change). They could qualify and quantify their crucial role and contribution in the dimension of Human Capital - at an organisational, group as well as individual level - to ultimately achieve organisational objectives whilst at the same time maintaining and promoting human well-being. They could, by way of illustration, ask themselves in what way they contribute and ensure that the manpower needs of the organisation are met, the value of the organisation's human capital is quantified, the value of this asset is appreciated, the asset is continually developed, maintained and nurtured, the contribution of every individual or group is optimised, valuable individuals are retained, unnecessary human losses are prevented, and the organisation is being promoted as an employer of choice. They could furthermore assess their role and contribution in the dimension of Leadership by asking themselves what they do to ensure that leaders are available, empowered, competent, dynamic, visionary, willing to lead and ethical in their behaviour. It much the same way it was envisaged that the process illustrated above could be followed to assess the role and contribution of the industrial psychologist in respect of each of the dimensions of the conceptual framework developed through this study.

The development of the conceptual framework by researchers who undoubtedly have strongly entrenched, personally constructed views and convictions regarding the research question should obviously be regarded as a possible limitation to the trustworthiness and credibility of the findings. This limitation should be considered against the background of the intended purpose of the study, namely to primarily propose a framework of thought to facilitate further exploratory research towards answering the question: What are the roles and contributions of industrial psychologists in organisations, qualified and explained in a discourse familiar to the enduser of their services - the organisation and its internal stakeholders. It should also be accepted that the study was exploratory by nature, and that none of the findings that were produced can be accepted unconditionally. For this reason the study was followed up by an empirical endeavour that aimed to illicit research input from practicing psychologists to provide further insights towards answering the relevant research question.

\section{REFERENCES}

Anderson, H. V., Lawrie, G. \& Shulver, M. (2000). The Balanced Scorecard vs. the EFQM Business Excellence Model which is the better strategic management tool? 2GC Active Management, 1-15.

Ahasan, R. \& Imbeau, D. (2003). Who belongs to ergonomics? An examination of the human factors community. Work Study, 52(3), 123-128.

Babbie, E. R. \& Mouton, J. (2001). The practice of social research. Cape Town: Oxford.

Cooper, J. R. (1998). A multidimensional approach to the adoption of innovation. Management Decision, 36(8), 492502.

Banister, P., Burman, E., Parker, I., Taylor, M. \& Tindall, C. (1994). Qualitative methods in psychology: A research guide. Philadelphia, PA: Open University Press.

Botha, M. E. (1996). The role and development of a personal scientific frame of reference. In J. Garbers (Ed.). Effective research in the social sciences. Pretoria: Van Schaik.

Denzin, N. K. \& Lincoln, Y. S. (2003). Collecting and interpreting qualitative materials ( $2^{\text {nd }}$ ed.). Thousand Oaks, CA: Sage.
Dul, J. \& Weerdmeester, B. (1994). Ergonomics for beginners. A quick reference guide. London: Taylor \& Francis.

Ethics Institute of South Africa (n.d.). Retrieved May 30, 2004 from http://www.ethicsa.org/article.php?story=20030903131 $239249 \&$ mode $=$ print

Fahey, L. (2003). Competitor scenarios. Strategy and Leadership, 31(1), 32-44.

Gergen, M. \& Gergen, K. J. (2003). Social constructionism: A reader. London: Sage.

Gordon, J. R. (1996). Organizational behavior. A diagnostic approach ( $5^{\text {th }} \mathrm{ed}$.). New Jersey: Prentice Hall.

Goulding, C. (2002). Grounded theory: A practical guide for management, business and market researchers. London: Sage.

Gratton, L. (2000). Living strategy. London: Prentice Hall.

Hair, J. F. (Jr.), Babin, B., Money, A. H. \& Samuel, P. (2003). Essentials in business research methods. Hoboken, NJ: Wiley.

Henry, J. (2002). Creative management. Leadership and Organizational Development Journal, 23(7), 408-417.

Hepworth, P. (1998). Weighing it up - a literature review of the Balanced Scorecard. Journal of Management Development, 17(8), 559-563.

Hesselbein, F., Goldsmith, M., \& Beckhard, R. (1998). The leader of the future: New visions, strategies and practices for the next era. Journal of Management Development, 17(4), 303304.

Ho, J. T. S. (1997). Corporate wellness programmes in Singapore: Effect on stress, satisfaction and absenteeism. Journal of Managerial Psychology, 12(3), 117-189.

Institute of Directors (2002). King II Report on Corporate Governance for South Africa. Johannesburg: Institute of Directors.

Invancevich, J. M. \& Matteson, M. T. (1996). Organizational behavior and management ( $4^{\text {th }}$ ed.). Chicago: Irwin.

Kaplan, R. S. \& Norton, D. P. (1996). The Balanced Scorecard: Translating strategy into action. Boston: HBS.

Kaplan, R. S. \& Norton, D. P. (2001). The strategy focused organization. Boston: HBS.

Kaplan, R. S. \& Norton, D. P. (2004). Strategy maps. Converting intangible assets into tangible outcomes. Boston: HBS.

Mauer, K.F. (1996). The art of scientific writing. In J. Garbers (Ed.). Effective research in the social sciences. Pretoria: Van Schaik.

Mauer, K. F. (1992). Die formulering van teoretiese en kwalitatiewe navorsingsvoorstelle. Johannesburg: Rand Afrikaans University.

Moalusi, K. P. (2001). Industrial psychology for the creation of new futures in turbulent times. Journal of Industrial Psychology, 27(4), 17-21.

Mouton, J. (1996). The nature and structure of the practice of science. In J. Garbers (Ed.).Effective research in the social sciences. Pretoria: Van Schaik.

Neuendorf, K. A. (2002). The content analysis guidebook. Thousand Oaks, CA: Sage.

Norton, D. P. (2003). The Balanced Scorecard 2003. Johannesburg: Institute for International Research.

Olve, N., Roy, J. \& Wetter, M. (2000). A practical guide to using the Balanced Scorecard. Chichester: John Wiley \& Sons.

Patton, M. Q. (2002). Qualitative research and evaluation methods ( $3^{\text {rd }}$ ed.). Thousand Oaks, CA: Sage.

Pfau, B. N. \& Kay, I. T. (2002). The human capital edge. 21 People management practices your company must implement (or avoid) to maximize shareholder value. New York: McGraw Hill.

Pienaar, Y. \& Roodt, G. (2001). Die teenswoordige en toekomstige rolle van Bedryfsielkundiges in Suid-Afrika. Journal of Industrial Psychology, 27(4), 25-33.

Prescott, B. (1998). Creating a world class organization. Ten performance measures of business success. London: Kogan Page.

Prinsloo, J. J., Moropodi, M. J., Slabbert, J. A. \& Parker, A. (1999). A perspective on the world-class company. Pretoria: Strat Excell. 
Rhinesmith, S. H. (1996). A manager's guide to globalization. Six skills for success in a changing world (2 ${ }^{\text {nd }}$ ed.). New York: McGraw Hill.

Rossouw, D. (2000). Intellectual tools: Skills for the human sciences. Pretoria: Amabhuku.

Rowan, M. P. \& Wright, P. C. (1995). Ergonomics is good for business. Facilities, 13(8), 18-25.

Schreuder, A. M. G. (1999). Die ontwikkeling van Bedryfsielkunde aan Suid-Afrikaanse universiteite: 'n Historiese oorsig en toekomsperspektief. Pretoria: UNISA.

Schreuder, A. M. G. (2001). The development of Industrial Psychology at South African universities: A historical overview and future perspective. Journal of Industrial Psychology, 27(4), 2-7.

Schwandt, T. A. (2001). Dictionary of qualitative inquiry ( $2^{\text {nd }}$ ed.). Thousand Oaks, CA: Sage.

Sluchak, T. J. (1992). Ergonomics: Origins, focus and implementation considerations. American Association of Occupational Health Nursing Journal, 40(3), 105-112.

South African Excellence Foundation (1997). The South African Excellence Model. Unpublished training manual.

Strauss, A. L. \& Corbin, J. M. (1998). Basics of qualitative research: Techniques and procedures for developing grounded theory $\left(2^{\text {nd }}\right.$ ed.). Thousand Oaks, CA; Sage.

Swink, M. \& Hegarty, W. H. (1998). Core manufacturing capabilities and their links to product differentiation. International Journal of Operations \& Production Management, 18 (4), 374-396.

Ulrich, D. (1997). Human resource champions. Boston: HBS.

Uys, T. \& Puttergill, C. (2000). Sampling. In D. Rossouw (Ed.).
Intellectual tools: Skills for the human sciences. Pretoria: Amabhuku.

Van der Merwe, H. (1996). The research process: Problem statement and research design. In J. Garbers (Ed.). Effective research in the social sciences. Pretoria: Van Schaik.

Van der Watt, H. H., Van Wijck, W. \& Von Benecke, M. (2001). The Balanced Scorecard and the Excellence Framework - Synergistic or totally different? Management Dynamics, 10(1), 47-66.

Van Riel, C. B. M. \& Balmer, J. M. T. (1997). Corporate identity: The concept, its measurement and management. European Journal of Marketing, 31(5/6), 340-355.

Veldsman, T. H. (2001). A new playing field, game and/or different rules? Into the future with Industrial Psychology as a discipline and profession. Journal of Industrial Psychology, 27(4), 34-41.

Venter, A. \& Barkhuizen, N. (2005). Rethinking undergraduate curricula: A Delphi study of Human Resource Management and Industrial and Organisational Psychology. Journal of Industrial Psychology, 31(3), 46-53.

Verwey, S. (2000). Content analysis. In D. Rossouw (Ed.). Intellectual tools: Skills for the human ciences. Pretoria: Amabhuku. Watkins, M. L. (2001). Industrial Psychology: An identity crisis and future direction. Journal of Industrial Psychology, 27(4), 8-13.

Willig, C. (2001). Introducing qualitative research in psychology: Adventures in theory and method. Buckingham, PA: Open University Press.

Wolcott, H.F. (2001). Writing up qualitative research (2nd ed.). Thousand Oaks, CA: Sage. 